\section{Dietary recommendations: comparing dietary guidelines from Brazil and the United States}

\author{
Recomendações dietéticas: comparação entre os \\ guias alimentares brasileiro e americano
}

\section{Abstract}

${ }^{1}$ Instituto de Medicina Social, Universidade do Estado do Rio de Janeiro, Rio de Janeiro, Brasil.

2 Department of Nutrition, Harvard School of Public Health, Boston, USA.

${ }^{3}$ Department of Epidemiology, Harvard School of Public Health, Boston, USA.

${ }^{4}$ Instituto de Nutrição Josué de Castro, Universidade Federal do Rio de Janeiro, Rio de Janeiro, Brasil.

5 Escola de Enfermagem, Universidade Federal de Minas Gerais, Belo Horizonte Brasil.

Correspondence R. A. Pereira

Departamento de Nutrição Social Aplicada, Instituto de Nutrição Josué de Castro, Universidade Federal do Rio de Janeiro.

Av. Carlos Chagas Filho 373

Rio de Janeiro, RJ 21941-590, Brasil.

roapereira@ufrj.br
The Brazilian dietary guidelines are based in part on mainstream United States' recommendations, in spite of the criticisms and shortcomings of the American guidelines. In this paper, Brazilian food guidelines are summarized and discussed in comparison with the USA recommendations. American and Brazilian dietary recommendations are quite similar in many aspects, particularly those related to variety in the diet, the importance of physical activity and weight management. Different to American guidelines, those from Brazil advise people to choose fresh foods, to prefer healthier types of fat, to limit trans fat intake and to eat good sources of protein, but does not recommend the consumption of whole grains. Besides the challenges related to their implementation, indicators for the evaluation of the effectiveness of these guidelines should be established from the beginning, particularly those related to changes in dietary habits and the prevalence of obesity.

Public Health Nutrition; Nutrition Policy; Health Promotion; Guideline
Rosely Sichieri 1

Stephanie E. Chiuve 2,3

Rosângela Alves Pereira 4

Aline Cristine Souza Lopes 5

Walter C. Willett 2,3

\section{Introduction}

Early dietary guidelines in the USA were created in the 1940s and aimed to meet intake requirements of essential nutrients to prevent deficiencies. A decade later in Brazil, the first official nutritional program was announced, aimed at preventing goiter, and not until the 1970s did guidelines and small programs in Brazil expand their focus to reduce overall undernutrition 1 . Brazilian efforts to incorporate nutritional recommendations related to chronic diseases into guidelines began in the 1990s 1 .

Dietary guidelines are designed to promote good nutrition and to address diet-related conditions. Based on evidences linked to the complex relationship between dietary factors and diseases, dietary guidelines intend to support food selection and portioning 2 .

In the USA, the dietary guidelines introduced at the end of the 19th century originally planned to deal with health problems related to nutrient deficiency. But from the late 1970s, the recommendations were shaped in order to avoid the harmful effects of diet on cardiovascular disease 2. In 1980, the US Department of Agriculture (USDA) in collaboration with the Department of Health and Human Services released the US Dietary Guidelines for Americans (DGA) to provide scientific-based advice to promote good health and reduce major chronic diseases. In 1992, the USDA introduced the Food 
Guide Pyramid, a graphic designed to promote the DGA, which was updated in $2005^{3}$.

In Brazil, initiatives aiming at dealing with endemic nutritional deficiency problems began timidly during the 1930s, and in the mid 1950s, the first program based on food distribution (the National School Meals Program) and a proposal aiming at the prevention of goiter were established. However, it was not until the 1970s that dietary guidelines and programs in Brazil expanded their focus in order to reduce overall undernutrition 1,4,5. Food-based guidelines related to the prevention of obesity and chronic diseases were academic and officially incorporated during the 1990s, following recommendations from the World Health Organization (WHO) 6 .

The DGA, the pyramid, and the processes behind their development have served as a template for dietary recommendations in many countries, including Brazil. The first food-based recommendation in Brazil relied on the total amount of portions per day and was presented as the Brazilian pyramid, which was also the basis for the development of mandatory food labeling, initiated in 2001 4,7. In 2002, the energy needs defined for mandatory labeling of food products were revised, reducing the daily total caloric intake used in the calculation of daily percentages of nutrients from 2,500 to $2,000 \mathrm{kcal}$ and introducing the amount of trans fat acids in foods.

In this article, the Brazilian food and nutritional guidelines are summarized and discussed in comparison with the North American recommendations, although the new pyramid design will not be considered because it has not been incorporated into the Brazilian guidelines.

\section{Four decades of dietary guidelines for Americans}

In the late 1970s, US dietary recommendations shifted towards the reduction of the cardiovascular disease burden, as these diseases had become the leading cause of morbidity and mortality. By this time, fat had become the major dietary villain, since blood lipids were established as a risk factor for cardiovascular disease and ecologic data showed a correlation between the proportion of energy provided for fat and obesity ${ }^{8}$. Furthermore, evidence from ecological and prospective epidemiologic studies, controlled feeding studies and randomized trials carried out in the 1960s indicated that replacing dietary saturated fat with polyunsaturated fat reduced serum cholesterol levels and the risk of cardiovascular disease as reviewed by $\mathrm{Hu} \&$ Willett 9 . Also, in the 1970s dietary recommendations pointed that reducing fat intake would decrease some cancer rates, including breast, colon, and prostate cancer 10.

According to Marantz et al. 8 (p. 234), the proposal for reducing dietary fat looked sensible and apparently risk-free "...despite the lack of direct evidence regarding either the ability to accomplish this shift or its cardiovascular and overall effects". Thus, standard dietary advice from the 1970s and early 1980s recommended replacing saturated fat with polyunsaturated fat. Also, the 1980 and 1985 revisions of the guidelines encouraged the replacement of all forms of fat with "complex" carbohydrates. In 1990, the guidelines signaled that the intake of fat should be less than $30 \%$ of total energy intake. The Food Guide Pyramid, published in 1992 11, reinforced the campaign to replace all types of fat with starch and failed to acknowledge that some fats are essential, even in the prevention of heart disease 3 . Despite the lack of convincing scientific evidence, there was the promising idea that low fat diets would result in diminished obesity rates. In this way, the 1995 edition of the dietary guidelines unambiguously reaffirmed the advice to reduce fat intake 8 .

The 2005 DGA report provides 41 recommendations, grouped into nine categories (Figure 1). In the 2005 DGA the value of unsaturated fat is acknowledged, the importance of varying the intake of different kind of vegetables is highlighted, and stricter limits on salt intake are proposed. Moreover, weight management and daily exercise are emphasized. On the other hand, the 2005 DGA fail in establishing strict cut-off values for trans fat and added sugar 3 .

Although the law defines that the DGA should be revised every five years, the Food Guide Pyramid did not change for more than a decade, while scientific advancements continuously showed the necessity of reviewing the principles displayed in the pyramid. The 2005 DGA was the base for the new Food Guide Pyramid, designated as MyPiramid 12, in which the icon, text and pictures have been removed and colored vertical areas represent the food groups.

According to Chiuve \& Willett 3 , even though the new icon is aesthetically pleasing, it introduced a high level of complexity, and as a result the understanding and application of the dietary principles may be compromised. The authors signaled that the colored stripes in MyPiramid deliver an ambiguous message related to food groups and disregard the inherent interpretability of the pyramid shape, which implicitly indicates that the items in the bottom can be consumed in greater amounts. Furthermore, MyPyramid is impossible to interpret away from the online tool, which is designed to provide individualized 


\section{DIETARY GUIDELINES FOR AMERICANS}

Adequate nutrients within energy needs

Consume a variety of foods within the food groups

Meet recommendations within energy needs through a balanced diet

Weight management

Maintain healthy body weight by balancing energy intake and expenditure

Prevent gradual weight gain over time through small decreases in food intake and increasing physical activity

Physical activity

Engage in regular moderate-intensity exercise

- 30 minutes to reduce disease risk

- 60-90 minutes for weight loss and maintenance

Food groups to encourage

Fruits and vegetables, whole grains (at least half of total grains) and dairy products (three servings daily)

Fats

Should provide $20-35 \%$ of dietary intake, mainly from unsaturated sources

No more than $10 \%$ of the dietary energy intake should come from saturated fat; less than $300 \mathrm{mg}$ cholesterol daily

Keep trans fat intake as low as possible

Choose protein sources low in fat

\section{Carbohydrates}

Choose fruits, vegetables and whole grains and foods low in added sugars and caloric sweeteners

\section{Sodium and potassium}

Limit sodium to 2,300mg (1 teaspoon of salt per day)

Choose foods high in potassium, such as fruits and vegetables

\section{Alcoholic beverages}

If you chose to drink alcoholic beverages, do so sensibly and in moderation

- 1 drink per day for women

- 2 drinks per day for men

Food safety

Keep food safe to eat

* Based on Chiuve \& Willett 3 .

recommendations based on estimated energy requirements, calculated from information on age, sex, and activity level and ignoring the most important determinant of energy needs - the body size (height and weight). Although the estimated energy value can be under or super estimated, the application provides extremely precise (and unrealistic) recommendations for each food group.
Facts and figures: fat as the main culprit in the increase of chronic diseases

From 1980 to 2000 the US cardiovascular mortality rates declined, a decline already initiated in the 1960s (before the dietary guidelines were elaborated) ${ }^{8}$. A recent meta-analysis, which classified the methodological quality of the studies, showed strong evidence for monounsaturated 
fatty acids and insufficient evidence of an association between saturated and total fat intake 13 on cardiovascular disease.

On the other hand, the reduction in the cardiovascular disease mortality was compensated by the increase in obesity and diabetes. Reports showing that the increased prevalence of obesity corresponded to an increase in carbohydrate consumption raised attention 14 . Nevertheless, an analysis that tracked the disease incidence and diets in over 100,000 North American women showed that the adherence to the dietary pattern promoted by the Food Guide Pyramid was only associated with a minimal reduction in the risk of major chronic disease 15 .

The 2000 edition of the DGA already recognized that lowering fat intake might be potentially harmful and presented concern with the deceptive idea that a low fat diet always means a healthy diet; in addition, there was an alert to the fact that reducing fat could result in overconsumption of carbohydrates and contribute to obesity ${ }^{8}$. Marantz et al. ${ }^{8}$ explained that these paradoxical figures reflected an increase in the denominator (total energy intake) instead of a reduction in the numerator (absolute fat intake). Thus, the increase in energy intake was credited with an increase in carbohydrate consumption and the absolute fat intake did not change significantly. There is no clear understanding about the physiological mechanisms that led to the increasing in carbohydrate and energy consumption accompanying the reduction in fat intake. Although it cannot be seen as a causal relationship, the synchronized phenomena of reduction in fat intake and rise in obesity rates pose a question about the effect of dietary advice 8 .

The prevalence of obesity (body mass index - $\mathrm{BMI}>30 \mathrm{~kg} / \mathrm{m}^{2}$ ) among women from the city of Rio de Janeiro, Brazil, increased notably from 1995 to 2005 ( $17 \%$ to $24 \%$ ). Over this ten-yearperiod, an overall statistically significant increase in energy intake (from 2,408 to 2,912kcal) was observed, while total lipid intake decreased among less educated women, but not among the more educated ones. Additionally, an overall reduction in cholesterol intake was observed 16 .

In summary, the long and rich history of building DGA did not exempt the US initiatives from making the wrong choices. In Brazil, the elaboration of dietary guidelines is a recent enterprise; thus it is important to learn from the lessons given by the American experience on dietary advice to prevent obesity and non-transmissible chronic diseases.

\section{Brazilian Dietary Guidelines}

The Brazilian Dietary Guidelines (BDG) were written by scientific committees of experts appointed by the Ministry of Health. The principles that underline the BDG are common to various dietary recommendations (such as those formulated by the WHO) and others specific to the Brazilian context, reflecting local culture and reasoning related to the prevention of diseases, healthy food and lifestyle. These principles are summarized in Table 1 . The BDG take into account the scientific state of the art on food intake and disease prevention added to considerations related to culture, food security, food safety and environmental sustainability, being presented for the general public, government agencies and industry, health professionals (particularly those involved in the primary services), and for the family context 17 .

The BDG have seven core guidelines, two special guidelines, and an annex addressing questions related to the processing and to the nutritional quality of the food, like genetically modified food, use of pesticides, hormones and medicines in food production, organic agriculture, industrial processing methods, artificial sweeteners, cooking methods, and ready-to-eat items (Table 2) 17.

BDG do not adopt a specific visual aid like the pyramid. Instead, there are different resources to aid the dissemination of the guidelines. Folders and banners displaying the Ten Steps to a Healthy Food and a pocket edition of the guidelines are the most accessible tools used in the promotion of the BDG, and both are written in non-academic language and are graphically attractive 18,19 .

\section{Comparison of the Brazilian and US dietary guidelines}

The American and Brazilian dietary recommendations are quite similar in many aspects, such as the advice to consume a varied diet, the importance of physical activity and weight management, suggested daily amounts of salt intake, recommendations on the number of milk and dairy portions, and advices related to food safety. However, several key differences exist between the two guidelines. The US dietary guidelines lack a strict cut-off for intake of added sugars; in contrast, the Brazilian Ministry of Health followed the WHO recommendation that sugar should account for no more than $10 \%$ of total energy intake. In doing so, the government found great opposition from sugar producers. The strong decision on sugar advice was an important public health issue, be- 
Table 1

Principles underlining the Brazilian Dietary Guidelines *

\begin{tabular}{|c|c|}
\hline Principle & Reasoning \\
\hline Integrated approaching & $\begin{array}{l}\text { The recommendations address non transmissible chronic diseases, transmissible infectious diseases and } \\
\text { nutritional deficiency }\end{array}$ \\
\hline Scientific basis plus culture & $\begin{array}{l}\text { The recommendations are based on the scientific consensus of an adequate food intake allied with } \\
\text { traditional Brazilian food habits }\end{array}$ \\
\hline Positive reference & $\begin{array}{l}\text { The guidelines are developed on the basis of a positive reference, emphasizing the advantages and } \\
\text { stimulating healthy food, instead of stating prohibitive sentences on certain food }\end{array}$ \\
\hline Determination of the amount & $\begin{array}{l}\text { The guidelines express amounts recommended for the food groups, sometimes as limits for consumption } \\
\text { or indicating the number of portions recommended }\end{array}$ \\
\hline Variability of the amount recommended & $\begin{array}{l}\text { The guidelines are expressed in proportions of total energy intake needed to maintain good health, } \\
\text { adopting as a parameter a healthy individual who needs to consume } 2,000 \mathrm{kcal} \text { a day; these guidelines } \\
\text { provide the basics which should be corrected in order to adapt to individual necessities }\end{array}$ \\
\hline The food is the reference & $\begin{array}{l}\text { The guidelines are expressed in terms of food and beverages, instead of referring to nutrients and other } \\
\text { food components }\end{array}$ \\
\hline Environmental sustainability & $\begin{array}{l}\text { The guidelines provide incentives for the intake of minimally processed food, and food that is } \\
\text { locally produced, recognizing the importance of regional food culture family production, based on } \\
\text { environmentally sustainable technology }\end{array}$ \\
\hline A Brazilian original guide & Even though supported by universal scientific principles, the guidelines are based on Brazilian food culture \\
\hline Multifocal approaching & $\begin{array}{l}\text { The guidelines are expressed in four ways: (a) directed to the general public, conceived to be used in } \\
\text { different informative and educational contexts; (b) directed to sectors of government and industry; (c) } \\
\text { directed to health professionals, both more technical and (d) directed to family members, with more } \\
\text { practical characteristics }\end{array}$ \\
\hline Healthy eating habits & $\begin{array}{l}\text { The guidelines attempt to indicate how to change food intake in daily life in order to promote health and } \\
\text { prevent diseases, including food safety, behavioral and emotional aspects }\end{array}$ \\
\hline
\end{tabular}

* Based on Ministério da Saúde 17.

cause the country is an important sugar producer and the second greatest per capita consumer in the world, after the USA.

Beyond recommending a reduction in salt consumption, the BDG also emphasize that fresh foods should be chosen instead of canned or processed foods, and states that changes in industrial processes are crucial to achieve reductions in salt intake. On the other hand, despite the fact that the upper limit for salt intake is similar between both guidelines, in Brazil, potassium intake is not mentioned at all, even though it is known that it may play an important role in blood pressure regulation.

BDG also incorporated the war on fat intake establishing limits on the intake of total, saturated and trans fats. However there are subtle differences in fat intake advice: the recommendation for total fat intake is lower in Brazil (15-30\% of energy intake) than in the USA (20-35\% of energy intake). Furthermore, while the US guidelines mention that fat should come from unsaturated sources, in Brazil it is recommended to prefer vegetables and olive oil and trans fatty acid free margarine.

Another difference in the Brazilian guidelines, when compared to those of the US, is a greater focus on sources of protein. Iron deficiency is the number one public health nutritional problem in Brazil, thus it is crucial to emphasize good sources of iron in the dietary guidelines. The intake of meats (including organ meat) and eggs is encouraged in the Brazilian guidelines. Although the BDG indicate the selection of healthier sources of protein, such as those sources low in saturated fat (such as beans and poultry) and those high in unsaturated fats (like nuts and fish), the balance between the risk of nutritional deficiency and of chronic disease still needs clearer messages.

The Brazilian guidelines prescribe the intake of complex carbohydrates provided by cereals and roots, yet the intake of whole grains is not strongly highlighted. On the other hand, the US guidelines clearly indicate that the intake of whole grains should comprise at least half of total grains. 
Table 2

Guiding principles in the Brazilian Dietary Guidelines *

Guideline 1: healthy food and meals

Guideline 2: cereals and roots

Guideline 3: fruits and vegetables

Guideline 4: beans

Guideline 5: milk and dairy, meat and eggs

Guideline 6: fat, sugar, and salt

Guideline 7: water

Special guideline 1: physical activity

Special Guideline 2: food safety
Have at least 3 meals per day and small snacks between the meals

Healthy meals are prepared with varied food and include vegetable and animal food

Exclusive breastfeeding is the better option for a healthy diet during the fist 6 months of life

Complex carbohydrates (starch) from cereals (preferably whole) and roots should provide 45 to $65 \%$ of total energy intake

It is recommended the intake of six portions of cereals and roots daily

It is recommended the intake of three portions of fruits and three portions of vegetables daily, aiming to provide 9 to $12 \%$ of total energy intake (for a 2,000kcal diet), weighing around $400 \mathrm{~g} /$ day

It is recommended the intake of one portion of beans daily; the proportion of rice:beans should be

$2: 1$. Beans should provide $5 \%$ of total energy intake

It is recommended the intake of three portions of milk and dairy and one portion of lean meat, fish or eggs. Adults should choose low fat milk and dairy

Oils and fats (preferably vegetable oils, olive oil and trans free margarine) should provide between 15 and $30 \%$ of total energy intake (one portion /day)

The limit for saturated fat is $10 \%$ of total energy intake

Trans fat should be limited to $1 \%$ of total energy intake (or $2 \mathrm{~g} /$ day for a $2,000 \mathrm{kcal}$ diet)

Simple sugars should account for a maximum of $10 \%$ of total energy intake (one portion/day)

Salt: $5 \mathrm{~g}$ /day plus the advice to reduce salty processed food such as: seasonings, concentrated broth,

sauces, salty-snacks, and industrialized soups

At least $2 \mathrm{~L}$ of water/daily

Offer regularly water to children and elders

Encourage physical activity that is appropriate for the individual's life stage and the maintenance of a healthy weight, at least 30 minutes daily

Prevention and control measures along the productive chain

* Based on Minstério da Saúde 17,18.

\section{Discussion}

Dietary guidelines must be considered at every level of government, from federal agencies, like the USDA, to county school boards. They are also important to the food industry and catering services among others.

A distortion in the use of dietary guidelines is related to the recommendations for trans fat in Brazil. The BDG provide recommendations for the maximum amount of trans fatty acid (no more than $1 \%$ of daily total energy intake) with the main idea of cutting this type of fat in the diet close to zero. Unfortunately, food industries have been tricking the recommendation by translating this limit ( $1 \%$ of total energy intake) into a maximum of $0.2 \mathrm{~g}$ of trans fat per portion of food and reducing the serving proposed in the label in such a way that the amount of trans fat is always below the maximum recommended per day. This marketing strategy has also been reinforced by claims such as "no trans fat", or "free of trans fat", or "zero trans fat". Therefore, many products made with vegetable trans fat are now sold as free of trans fat.

Also, the modifications on industrialized and ready-to-eat foods made in order to reach the recommendations on trans fat have introduced other distortions in their fat content, as showed by Gagliardi et al. ${ }^{20}$ who chemically analyzed some industrialized items, such as creamy margarine, plant sterol margarine, stuffed sweet cookies, salty crackers, and French fries and hamburgers from a multinational fast food chain, all of which claimed to be trans fat free. Despite the reduction in trans fatty acid amounts, these foods contained large concentrations of saturated fats. These are some of the problems related to the compliance to the dietary guidelines that should be faced by health authorities.

Woolf \& Nestle 21 signaled that it is not reasonable to suppose that a guideline per se can change the nation's eating habits, food preferences, portion sizes, and physical activity levels. Those factors are produced by the "obesogenic" environment. Nevertheless, the guidelines 
should be improved and redesigned to reach the proposed objectives. The authors advocate that the solution is not to condemn and abandon the guidelines, but to look for strategies directed at the transformation of the environment, to introduce new concepts like the differentiation between "good" and "bad" fats, and to address caloric intake, portion size, physical inactivity, and other contributors to obesity 21.

Yngve \& Margetts 22 suggested that it is possible that the dietary guidelines are not reaching those who are most in need of these kinds of advice, and who, usually, are more resistant to changes. The authors have recommended other approaches to improve food intake which could get the attention of these groups, from diversifying visual aids to modifying the form of the recommendations, for example icons delivering specific messages for particular situations, like schools, street markets, vending machines, supermarkets, restaurants etc. Another alternative is using the proposal of Monteiro 23 to classify foods to deal with the problem that, apart from fresh food, most of the items available to purchase are mixtures of the traditional food groups and do not fit into the traditional categories of food presented in most of the dietary guidelines.

Monteiro's new approach 23 classifies foods into three groups according to the level of processing: (1) minimally processed, like meat, milk, grains, pulses, fruits, vegetables; (2) foods resulting from substances extracted from whole foods, like flour, oil, and sugar; (3) the ultra-processed foods, like breads and rolls, cookies, ice-cream, chocolate, confectionery, breakfast cereals, cereal bars, chips and salty snacks etc. This new categorization could be more easily translated into a shopping list favoring the understanding and the application of guidelines.

Chiuve \& Willett ${ }^{3}$ also indicated that there are alternatives other than the US pyramid for reinforcing healthy eating, such as the Mediterranean, Latin and Asian Pyramids 24. They use specific cultural eating patterns to offer evidence-based advice for healthy eating. A traditional Mediterranean diet, for example, high in fruits, vegetables, nuts, unrefined grains and olive oil, with a moderate intake of fish and alcohol, and a low intake of meat and dairy products is inversely associated with total and cardiovascular mortality 25,26.

In this line, Brazil should stimulate research and make efforts to develop a more cultural based icon for advertising healthy diet. As emphasized by Chiuve \&Willett 3 it is imperative that this icon provides scientifically derived recommendations to aid the public in making healthy food selec- tions. The core of MyPyramid lies on the premise that "there is no such thing as a good or bad food", which reflects current USDA policy and, perhaps not coincidentally, the mantra of the dominant forces of the US food industry.

Moreover, it is important to evaluate the power of penetration of the BDG and how it is understood by the targets of the recommendations, including the general public, health professionals, policymakers, and the industrial sector; as well as how applicable the recommendations are and to degree to which the guidelines are complied with. Also, the effectiveness of the BDG should be evaluated using epidemiological data on food consumption, obesity and other markers of nontransmissible chronic diseases, using validated standardized methods and comparable populations. Brazil already has a national strategy for assessing risk factors for the chronic diseases - VIGITEL (Telephone Survey System for the Surveillance of Risk and Protective Factors for Chronic Non-Communicable Diseases) 27,28,29, which could include more indicators of the effectiveness of the guidelines, although national surveys on individual food habits have not been carried out in a systematic way.

Learning from experiences developed in other scenarios is crucial to improve the effectiveness of the dietary guidelines. Yngve \& Margetts 22 cited that the use of a "traffic light" system to indicate if foods are more or less healthy adopted by the UK Food Standards Agency is considered very understandable. Also, the basic idea that scientifically sound principles should be the basis of recommendations is not an easy task, as shown by a systematic review of the evidence supporting a causal link between dietary factors and coronary heart disease 13 . For an indicator of quality of carbohydrate - the glycemic index - it has been shown strong evidence of an association with cardiovascular disease 13 and this indicator has been extensively used in Australia. Neither US nor Brazilian guidelines have included foods based on their glycemic index in the recommendations, although Brazilian guidelines reinforce the importance of eating beans a positive aspect of this recommendation since beans is one of the foods with the smallest glycemic index 30 .

In this review many targets of recommendations were given insufficient evidence for factors such as: intake of supplementary vitamin $\mathrm{E}$ and vitamin C; saturated and polyunsaturated fatty acids; total fat; linolenic acid, meat, eggs, and milk.

There remain many more challenges to face in implementing the dietary guidelines, for example the establishment of effective messages 


\section{References}

1. Leão MM, Castro IR. Políticas públicas de alimentação e nutrição. In: Kac G, Sichieri R, Gigante DP, organizadores. Epidemiologia nutricional. Rio de Janeiro: Editora Fiocruz/Editora Atheneu; 2007. p. 519-41.

2. Davis C, Saltos E. Dietary recommendations and how they have changed over time. In: Frazão E, editor. America's eating habits: changes and consequences. Washington DC: US Department of Agriculture/Economic Research Service; 1999. p. 33-50. (Agriculture Information Bulletin, 750).

3. Chiuve SE, Willett WC. The 2005 Food Guide Pyramid: an opportunity lost? Nat Clin Pract Cardiovasc Med 2007; 4:610-20.

4. Sichieri R, Coitinho DC, Monteiro JB, Coutinho WF Recomendações de alimentação e nutrição saudável para a população brasileira. Arq Bras Endocrinol Metab 2000; 44:227-32.

5. Silva AC. De Vargas a Itamar: políticas e programas de alimentação e nutrição. Estud Av 1995; 9:99-107.

6. Sichieri R. Is fat intake important in the public health control of obesity? Am J Clin Nutr 2000; 72:203-6.

7. Philippi ST, Latterza AR, Cruz ATR, Ribeiro LC. Pirâmide alimentar adaptada: guia para escolha dos alimentos. Rev Nutr 1999; 12:65-80.

8. Marantz PR, Bird ED, Alderman MH. A call for higher standards of evidence for dietary guidelines. Am J Prev Med 2008; 34:234-40.

9. Hu FB, Willett WC. Optimal diets for prevention of coronary heart disease. JAMA 2002; 288:2569-78.

10. Palmer S, Bakshi K. Diet, nutrition, and cancer: interim dietary guidelines. J Natl Cancer Inst 1983; 70:1151-70.

11. United States Department of Agriculture Human Nutrition Information Service. The food guide pyramid (1992). http://www.everydiet.org/diet/foodpyramid-old (accessed on 19/Jun/2009) .

12. Center for Nutrition Policy and Promotion, United States Department of Agriculture. MyPyramid: steps for a healthier you. Washington DC: United States Department of Agriculture; 2005.

13. Mente A, Koning L, Shannon HS, Anand SS. A systematic review of the evidence supporting a causal link between dietary factors and coronary heart disease. Arch Intern Med 2009; 169:659-69.

14. Willett WC. Is dietary fat a major determinant of body fat? Am J Clin Nutr 1998; 67(3 Suppl):556S$62 \mathrm{~S}$.

15. McCullough ML, Feskanich D, Stampfer MJ, Rosner BA, Hu FB, Hunter DJ, et al. Adherence to the Dietary Guidelines for Americans and risk of major chronic disease in women. Am J Clin Nutr 2000; 72:1214-22.

16. Andrade RG, Pereira RA, Sichieri R. Ten-year increase in the prevalence of obesity and reduction of fat intake in Brazilian women. J Epidemiol Community Health; in press.

17. Coordenação Geral da Política de Alimentação e Nutrição, Secretaria de Atenção a Saúde, Ministério da Saúde. Guia alimentar para a população brasileira: promovendo a alimentação saudável. Brasília: Ministério da Saúde; 2006.
18. Coordenação Geral da Política de Alimentação e Nutrição, Secretaria de Atenção à Saúde, Ministério da Saúde. Dez passos para uma alimentação saudável. http://nutricao.saude.gov.br/ documentos/10passos_adultos.pdf (accessed on 19/Jun/2009).

19. Coordenação Geral da Política de Alimentação e Nutrição, Secretaria de Atenção à Saúde, Ministério da Saúde. Guia alimentar de bolso para a população brasileira: promovendo a alimentação saudável. Brasília: Ministério da Saúde; 2007.

20. Gagliardi ACM, Mancini FJ, Santos RD. Perfil nutricional de alimentos com alegação de zero gordura trans. Rev Assoc Med Bras 2009; 55:50-3.

21. Woolf SH, Nestle M. Do dietary guidelines explain the obesity epidemic? Am J Prev Med 2008; 34:263-5.

22. Yngve A, Margetts B. Building centres of excellence, and a new approach to food guides. Pub Health Nutr 2009; 12:589-90.

23. Monteiro CA. Nutrition and health: the issue is not food, nor nutrients, so much as processing. Public Health Nutr 2009; 12:729-31.

24. Oldways Preservation and Exchange Trust. Introduction to traditional diet pyramids. http://www. oldwayspt.org/eating-well/introduction-tradi tional-diet-pyramids (accessed on 08/Jun/2009).

25. Lorgeril M. Mediterranean diet in the prevention of coronary heart disease. Nutrition 1998; 14:55-7.

26. Trichopoulou A, Costacou T, Bamia C, Trichopoulos D. Adherence to a Mediterranean diet and survival in a Greek population. N Engl J Med 2003; 348:2599-608.

27. Secretaria de Gestão Estratégica e Participativa, Secretaria de Vigilância em Saúde, Ministério da Saude. VIGITEL Brasil 2006. Vigilância de fatores de risco e proteção para doenças crônicas por inquérito telefônico. Brasília: Ministério da Saude; 2007.

28. Secretaria de Gestão Estratégica e Participativa, Secretaria de Vigilância em Saúde, Ministério da Saude. VIGITEL Brasil 2007. Vigilância de fatores de risco e proteção para doenças crônicas por inquérito telefônico. Brasília: Ministério da Saude; 2008.

29. Secretaria de Gestão Estratégica e Participativa, Secretaria de Vigilância em Saúde, Ministério da Saude. VIGITEL Brasil 2008. Vigilância de fatores de risco e proteção para doenças crônicas por inquérito telefônico. Brasília: Ministério da Saude; 2009.

30. Sichieri R, Moura AS, Genelhu V, Hu F, Willett WC. Eighteen-month follow-up of a randomized trial of low as compared to high-glycemic index diet on the prevention of obesity among Brazilian women. Am J Clin Nutr 2007; 86:707-13.

Submitted on 22/Jun/2009

Final version resubmitted on 23/Oct/2009

Approved on 04/Feb/2010 